\title{
SEX RATIO, POVERTY, AND CONCURRENT PARTNERSHIPS AMONG MEN AND WOMEN IN THE UNITED STATES: A MULTILEVEL ANALYSIS
}

\author{
Adaora A. Adimora, $\mathbf{M D}^{1,2,3}$, Victor J. Schoenbach, $\mathbf{P h D}^{2,3}$, Eboni M. Taylor, $\mathbf{P h D}^{2}$, Maria R. \\ Khan, $\mathbf{P h D}^{4}$, Robert J. Schwartz, $\mathbf{M A}^{3}$, and William C. Miller, $\mathbf{M D}^{1,2}$ \\ ${ }^{1}$ University of North Carolina School of Medicine, Chapel Hill, NC \\ ${ }^{2}$ UNC Gillings School of Global Public Health, Chapel Hill, NC \\ ${ }^{3}$ Cecil G. Sheps Center for Health Services Research at the University of North Carolina at \\ Chapel Hill, Chapel Hill, NC \\ ${ }^{4}$ College of Public Health and Health Professions, University of Florida, Gainesville, FL
}

\begin{abstract}
Purpose-Social and economic contextual factors may promote concurrent sexual partnerships, which can accelerate population HIV/STI transmission and are more common among African Americans than U.S. Whites. We investigated the relationship between contextual factors and concurrency.
\end{abstract}

Methods-We analyzed past-12-month concurrency prevalence in the 2002 National Survey of Family Growth and its contextual database in relation to county sex ratio (among respondent's racial/ethnic group), percentage in poverty (among respondent's racial/ethnic group), and violent crime rate. Analyses examined counties with balanced $(0.95-1.05$ males/female) or low $(<0.9)$ sex ratios.

Results-Concurrency prevalence was greater (OR; 95\% CI) in counties with low sex ratios $(1.67 ; 1.17,2.39)$, more poverty (OR 1.18; $0.98,1.42$ per 10 percentage-point increase), and higher crime rates (OR 1.04; 1.00,1.09 per 1,000 population/year). Notably, 99.5\% of Whites and $93.7 \%$ of Hispanics, but only $7.85 \%$ of Blacks, lived in balanced sex ratio counties; about $5 \%$ of Whites, half of Hispanics and three-fourths of Blacks resided in counties with > 20\% same-race poverty.

(c) 2013 Elsevier Inc. All rights reserved.

Corresponding author: Adaora A. Adimora, MD, MPH, Division of Infectious Diseases, 130 Mason Farm Road, CB \#7030, UNC School of Medicine, University of North Carolina at Chapel Hill, Chapel Hill, North Carolina 27599-7030, adimora@med.unc.edu, Tel: 919-843-0723, Fax: 919-966-6714.

Publisher's Disclaimer: This is a PDF file of an unedited manuscript that has been accepted for publication. As a service to our customers we are providing this early version of the manuscript. The manuscript will undergo copyediting, typesetting, and review of the resulting proof before it is published in its final citable form. Please note that during the production process errors may be discovered which could affect the content, and all legal disclaimers that apply to the journal pertain. 
Conclusions-The dramatic Black-White differences in contextual factors in the US and their association with sexual concurrency could contribute to the nation's profound racial disparities in HIV infection.

\section{Keywords}

Concurrent partnerships; African Americans; HIV; epidemiology; multilevel analysis; sex ratio; Hispanics

\section{INTRODUCTION}

Concurrent sexual partnerships, which can accelerate the spread of HIV infection through a sexual network, are more common among African Americans than among US Whites.[1], [2], [3] The differential in concurrent partnerships has been attributed to social and contextual factors, such as the ratio of men to women (the sex ratio) and community-level poverty.[5], [6] The sex ratio among African Americans is notoriously low due to increased mortality of Black men from disease and violence. In situations where the sex ratio is low, the sex with fewer members may have increased dyadic power, enabling them to obtain sexual favors with decreased commitment and avoid the constraints of monogamy.[7], [8], [9]) Poverty and social disorganization may also interfere with marriage and with postponement of sexual debut, thereby making individuals more likely to engage in concurrency.[5], [6] To date, there has been limited empirical investigation of the possible importance of contextual factors, such as the sex ratio and social and economic environment, in influencing sexual partnering patterns. We analyzed contextual data from a national survey to evaluate the relation of heterosexual concurrent partnerships to two contextual factors: the sex ratio and neighborhood poverty.

\section{METHODS}

The National Survey of Family Growth (NSFG) is conducted periodically by the U.S. National Center for Health Statistics (NCHS) using area probability samples designed, after analytic adjustment, to be representative of adults 15-44 years old in the civilian noninstitutionalized US population (including all 50 states and the District of Columbia) [10]. We analyzed data from the 12,571 respondents (7,643 females, 4,928 males) in Cycle 6, who were selected by a stratified, multistage probability sampling process with oversampling of people age 15 to 19 years, African-Americans, and Hispanics. During March 2002 through February 2003, trained female interviewers used computer-assisted personal interviewing (CAPI) to conduct confidential in-person interviews. Only one person per selected household was interviewed. Audio computer-assisted self-interviewing (ACASI) was used for questions deemed particularly sensitive.

Each NSFG respondent has a linked record in the NSFG Contextual Data File, which provides information about the respondent's community. The information was gathered from a variety of data sources, including the 2000 Census and the County and City Data Book.[11] Analyses of the contextual data file require approval by NCHS and must be conducted at one of several NCHS-approved facilities or via a remote submission procedure that restricts how often and which programs can be run and what output can be received. 
The primary outcome for our contextual analyses was concurrent sexual partnerships in the 12 months preceding the interview, determined as in our previous individual-level analyses of these data: a respondent was coded as having had a concurrent sexual partnership in the past year if the calendar month in which the first episode of sexual intercourse with one partner preceded the calendar month in which intercourse with an earlier partner last occurred.[1], [2], [3]

We selected variables from the contextual data file based on a conceptual model for understanding the role of individual and neighborhood factors in concurrent partnerships. [5, 6] In the model, neighborhood characteristics (socioeconomic features, demographic composition, mate availability, and level of social disorganization, such as crime rate) create an opportunity structure that influences social norms and affects individuals' likelihood of engaging in particular behaviors, such as concurrent sexual partnerships. Neighborhood variables affect concurrency through individual-level characteristics,[12] which as the more proximate influences on behavior may mediate the effects of community attributes on concurrency.[12], [13]

The primary exposure of interest was a low sex ratio among county residents of the respondent's race/ethnicity. Sex ratios were calculated by dividing the size of the male population aged 15 through 44 in each respondent's county for each race/ethnicity (White, Black, or Hispanic) by the size of the corresponding (county, age, race/ethnicity) female population. Analyses using sex ratios for different levels of aggregation (block group, tract, county) and age range $(15-44,15-64)$ yielded similar results. Our contextual analyses compared respondents according to whether the age 15-44 county sex ratio for their racial/ ethnic group was low ( $₫ .90)$ or balanced (0.95-1.05), since these two categories have the clearest theoretical expectation from our conceptual model.[5], [6] Respondents who resided in counties with sex ratios greater than 0.9 and less than 0.95 or greater than 1.05 were not included in the contextual analyses.

We analyzed percentage of the respondent's race/ethnicity in poverty as an indicator of economic adversity. We analyzed the overall rate of violent crimes for the county as an indicator of social disorganization.

\section{Analysis}

Analyses of the associations between contextual variables and concurrency used the RLOGIST procedure in SAS-callable SUDAAN with concurrency as the dependent variable, among the 6,844 respondents who had ever had intercourse and lived in counties with low or balanced sex ratios. We examined the relation between concurrency and each contextual variable by itself and with adjustment for the other contextual variables. We fit multilevel models with contextual variables and individual-level variables that were related to concurrency in our individual-level analyses and not regarded as causal intermediates.[1], [2], [3] We conducted analyses overall, by gender, and by race/ethnicity. Statistical analyses, carried out with SAS and SUDAAN (versions 10.0 and 11.0), incorporated the NCHSprovided sample weights and accounted for the NSFG's complex sampling design ([14]: Appendix VI).

Ann Epidemiol. Author manuscript; available in PMC 2014 November 01. 


\section{RESULTS}

Distributions of the contextual variables among all NSFG respondents are shown in Table 1. The median respondent lived in a county where the sex ratio was 1.01 overall, median 1999 annual household income was $\$ 42,189$ (1999 dollars), the overall annual rate of violent crime was 435 per 100,000 county residents, and $9.8 \%$ of the respondent's racial/ethnic group lived below the poverty line. As in our previous analyses for men[2] and women,[1], [3] older age at time of interview and older age at first intercourse were both associated with lower concurrency prevalence among all NSFG respondents, whereas substance use and being unmarried were associated with higher concurrency prevalence (Table 2).

In bivariate analyses with the contextual variables for respondents in counties with low or balanced sex ratios (Table 3), low sex ratio (versus balanced: OR: 2.22; CI: 1.69, 2.94), poverty in the respondent's racial/ethnic group (per 10 percentage point increase: OR: 1.52; CI: 1.33, 1.74), and violent crime (crimes per 1,000 persons/year increase, OR: 1.08; CI: $1.04,1.13)$ were each associated with higher prevalence of concurrency. As expected, mutually-adjusted ORs were smaller, but none of the associations could be explained by the other two: low sex ratio (OR: 1.46; CI: $0.98,2.17)$, poverty in the respondent's racial/ethnic group (OR: 1.23; CI: 0.98, 1.54), violent crime (OR: 1.05; CI: 0.99, 1.11).

In multilevel models in these same counties (Table 4), low sex ratio (OR: 1.67; CI: 1.17, 2.39), poverty in the respondent's racial/ethnic group (OR: 1.18; CI: 0.98, 1.42), and violent crime rate (OR: 1.04; CI: 1.00,1.09) as well as three individual-level variables (age at interview, age at first intercourse, substance abuse) remained associated with concurrency, with odds ratios similar to but slightly smaller than the corresponding odds ratios in the individual-level analysis among respondents in all counties. A term for male sex was also associated with concurrency in the multilevel model.

We were unable to control for or conduct separate analyses by racial/ethnic group because the sex ratio distributions had insufficient overlap across racial/ethnic groups. Among respondents in our analytic sample, virtually all whites (99.5\%) and the vast majority of Hispanics (93.7\%) resided in counties with a balanced (0.95-1.05) sex ratio. Conversely, only $7.85 \%$ of blacks in the sample resided in a county whose ratio was balanced. Thus, restriction of range of sex ratio obstructed our ability to analyze the relationship between sex ratio and concurrency between and within racial/ethnic groups.

There was also limited overlap among racial/ethnic groups in percentages of people living in poverty: among all NSFG respondents, only $5 \%$ of whites, compared to half of Hispanics and about three-fourths of Blacks, lived in counties where more than one in five households in their racial/ethnic group were below the poverty line.

\section{DISCUSSION}

Social determinants are recognized as drivers of behavior and disease outcomes. Sexual network patterns, such as concurrent partnerships, are critical determinants of population HIV spread. We analyzed a high quality nationally representative data set that oversampled Blacks and Hispanics and includes a contextual database to examine the relation between 
concurrent sexual partnerships and three contextual variables: sex ratio, poverty, and violent crime as an indicator of social disorganization. Concurrent sexual partnerships were more prevalent in counties with (1) low $(<0.9)$ sex ratios for the respondent's racial/ethnic group compared to balanced (0.95-1.05) sex ratios, (2) higher percentages of people of the respondent's racial/ethnic group in poverty, and (3) higher rates of violent crime. In a multilevel analysis that included previously identified individual-level correlates of concurrency (such as substance use and early age at first sexual intercourse), the three contextual factors remained associated with concurrency (although estimates were slightly less precise). These findings provide empirical support to social science theories that emphasize the role of the sex ratio in establishing and maintaining sexual network patterns. [7], [8]

The most striking observation of this study, however, is our inability to conduct analyses examining the relationship of a low sex ratio to concurrency within racial/ethnic groups due to the scarcity of low county sex ratios among Whites (and Hispanics) and the scarcity of balanced county sex ratios among Blacks. Limited overlap between Blacks and Whites was also observed for community poverty. These dramatically different distributions of county sex ratio and poverty underscore the stark contrasts in the context of life for African Americans and Whites in the US and highlight potential pathways between social inequities and racial disparities in HIV rates.

Although several studies[13], [15], [16] have found associations between neighborhood disadvantage and sexual activity or related outcomes, the relationship of neighborhood context to either multiple or concurrent partnerships is less clear.[17], [18] Like our study, a Zambian study demonstrated that men who resided in a district with a low sex ratio and decreased income earning opportunities for women were more likely to participate in extramarital sexual activity.[19] Similarly, an analysis of the 31,126 men and women in the National Health and Nutrition Examination Survey (NHANES) found that Black men in counties with a low sex ratio (calculated after subtracting the number of inmates in county correctional facilities) and high Black male incarceration rates were more likely to have multiple partners than were men in counties where the ratios were more balanced.[20] That study also noted the marked racial differences in the same-race sex ratio, with a much lower mean sex ratio and much higher incarceration rate for Blacks than either Whites or Mexican Americans.

The sex ratio is a key determinant of sexual network and marital patterns.[7] A relative scarcity of men disadvantages women in their attempts to negotiate and maintain mutually monogamous partnerships: men can easily enter another relationship if they feel their primary relationship is problematic.[21] In addition, men with multiple concurrent partnerships may be confident that their primary partner will not end the relationship because primary partnerships may be relatively difficult for women to obtain.[22]

Poverty is another determinant of long-term sexual partnership formation.[9], [8] Economic adversity works in tandem with the low sex ratio to undermine the stability of partnerships in black communities. Poverty, common among African Americans, decreases the feasibility and stability of marriage.[8], [9] The "male marriageable pool index" (the ratio of the 
number of employed civilian men to the number of women of the same race and age group) measures the combined impact of low sex ratio and unemployment on the "marriage market."'[23] As the proportion of young African American men who could financially support a family fell during the latter part of the twentieth century, the male marriageable pool index plummeted among young black adults.[23] Therefore, demographic features (such as this population's low sex ratio), economic conditions (such as unemployment and poverty), and the interplay between demographic and economic factors may conspire to promote concurrency and partner change among African Americans.[5], [6]

Several methodological issues are relevant. As in our previous publications,[1], [2], [3] we identified concurrent partnerships by comparing dates of first and last sexual intercourse with different partners during the past year. This method yields a concurrency indicator recommended by a UNAIDS working group,[24], [25] but it does rely on respondents' selfreport of dates. These dates were sometimes missing and, in other cases, may have been inaccurate in ways that affected the classification of concurrency. We used a binary variable for sex ratio instead of coding it as a continuous or ordinal variable because our objective was to evaluate the effect of a low sex ratio compared to the relatively balanced ratio that exists in the overall US population of reproductive age.

In conclusion, this study documents associations between sexual network patterns that promote HIV transmission and contextual factors that differ dramatically for Blacks and Whites, reflecting incommensurable differences in experience of these two ethnic groups. [26] These findings can contribute to our understanding of the profound racial disparities in HIV and other STIs that prevail in the US. These stark contrasts in the context of life are shaped by the distribution of money, power, and resources and are recognized as fundamental drivers of behaviors, health, and health disparities.[27] Individual level biomedical and behavioral preventive interventions, although critical, do not obviate the need for interventions that address contextual factors.[28] Pervasive inequities must be rectified.

\title{
Acknowledgments
}

Funding support: This study was supported by the National Institute of Child Health and Human Development, National Institutes of Health (5 K24HD059358-02, 1R21HD054293-01A1 to A. Adimora). E.M. Taylor was supported as a predoctoral fellow by the National Institute of Allergy and Infectious Diseases, National Institutes of Health (5T32AI007001-33: Training in Sexually Transmitted Diseases and AIDS, University of North Carolina at Chapel Hill), and M.R. Khan was supported as a postdoctoral fellow by the National Institute on Drug Abuse, National Institutes of Health, (5T32 DA07233, National Development and Research Institutes).

We greatly appreciate the assistance of Deborah Rose and the NCHS.

We dedicate this manuscript to the memory of Dr. Andrew Kaplan with gratitude for his unceasing support.

\section{LIST OF ABBREVIATIONS}

\author{
NSFG National Survey of Family Growth \\ NCHS National Center for Health Statistics \\ CAPI Computer-assisted personal interviewing
}


$\begin{array}{ll}\text { ACASI } & \text { Audio computer-assisted self-interviewing } \\ \text { NHANES } & \text { National Health and Nutrition Examination Survey }\end{array}$

\section{References}

1. Adimora A, Schoenbach V, Bonas D, Martinson F, Donaldson K, Stancil T. Concurrent Sexual Partnerships among Women in the United States. Epidemiology. 2002; 13:320-327. [PubMed: 11964934]

2. Adimora AA, Schoenbach VJ, Doherty IA. Concurrent sexual partnerships among men in the United States. Am J Public Health. 2007; 97:2230-2237. [PubMed: 17971556]

3. Adimora AA, Schoenbach VJ, Taylor EM, Khan MR, Schwartz RJ. Concurrent partnerships, nonmonogamous partners, and substance use among women in the United States. Am J Public Health. 2011; 101:128-136. [PubMed: 20724694]

4. Adimora AA, Schoenbach VJ, Martinson FE, Coyne-Beasley T, Doherty I, Stancil TR, et al. Heterosexually transmitted HIV infection among African Americans in North Carolina. J Acquir Immune Defic Syndr. 2006; 41:616-623. [PubMed: 16652036]

5. Adimora AA, Schoenbach VJ. Contextual Factors and the Black-White Disparity in Heterosexual HIV Transmission. Epidemiology. 2002; 13:707-712. [PubMed: 12410013]

6. Adimora AA, Schoenbach VJ. Social context, sexual networks, and racial disparities in rates of sexually transmitted infections. J Infect Dis. 2005; 191:S115-122. [PubMed: 15627221]

7. Guttentag, M.; Secord, P. Too Many Women: The Sex Ratio Question. Beverly Hills: Sage; 1983.

8. Tucker, MBT.; Mitchell-Kernan, CM. Trends in African American family formation: A theoretical and statistical overview. In: Tucker, MBT.; Mitchell-Kernan, CM., editors. The Decline in Marriage Among African Americans: Causes, Consequences and Policy Implications. New York: Russell Sage Foundation; 1995.

9. Ross, H.; Sawhill, I. Time of Transition: The Growth of Families Headed by Women. Washington, DC: The Urban Institute; 1975.

10. Lepkowski J, Mosher W, Davis K. National Survey of Family Growth, Cycle 6: Sample design, weighting, imputation, and variance estimation. Vital and Health Statistics. 2006:2.

11. Centers for Disease Control and Prevention. Other Cycle 6 Data Files. 2005.

12. Billy J, Moore D. A multilevel analysis of marital and nonmarital fertility in the U.S. Social Forces. 1992; 70:977-1011.

13. Brewster KL. Neighborhood context and the transition to sexual activity among young black women. Demography. 1994; 31:603-614. [PubMed: 7890095]

14. Lepkowski JM, Mosher WD, Davis KE, Groves RM, van Hoewyk J, Willem J. National Survey of Family Growth, Cycle 6: sample design, weighting, imputation, and variance estimation. Vital Health Stat. 2006; 2:1-82.

15. Fichtenberg CM, Jennings JM, Glass TA, Ellen JM. Neighborhood socioeconomic environment and sexual network position. J Urban Health. 2010; 87:225-235. [PubMed: 20140533]

16. Lindberg LD, Orr M. Neighborhood-level influences on young men's sexual and reproductive health behaviors. Am J Public Health. 2011; 101:271-274. [PubMed: 21228293]

17. Smith AM, Subramanian SV. Population contextual associations with heterosexual partner numbers: a multilevel analysis. Sex Transm Infect. 2006; 82:250-254. discussion 254. [PubMed: 16731679]

18. Senn TE, Carey MP, Vanable PA, Urban MA, Sliwinski MJ. The male-to-female ratio and multiple sexual partners: multilevel analysis with patients from an STD clinic. AIDS Behav. 2010; 14:942-948. [PubMed: 18483848]

19. Benefo KD. Determinants of Zambian men's extra-marital sex: a multi-level analysis. Arch Sex Behav. 2008; 37:517-529. [PubMed: 17999170] 
20. Pouget ER, Kershaw TS, Niccolai LM, Ickovics JR, Blankenship KM. Associations of sex ratios and male incarceration rates with multiple opposite-sex partners: potential social determinants of HIV/STI transmission. Public Health Rep. 2010; 125 (Suppl 4):70-80. [PubMed: 20626195]

21. Aral SO. Sexual network patterns as determinants of STD rates: paradigm shift in the behavioral epidemiology of STDs made visible. Sex Transm Dis. 1999; 26:262-264. [PubMed: 10333278]

22. Thomas JC, Thomas KK. Things ain't what they ought to be: social forces underlying racial disparities in rates of sexually transmitted diseases in a rural North Carolina county. Soc Sci Med. 1999; 49:1075-1084. [PubMed: 10475671]

23. Wilson, WJ. Truly Disadvantaged: The Inner City, The Underclass, and Public Policy. Chicago: The University of Chicago Press; 1987.

24. UNAIDS Reference Group on Estimates M, and Projections: Working Group on Measuring Concurrent Partnerships. Consultation on concurrent sexual partnerships: Recommendations from a meeting of the UNAIDS Reference Group on Estimates, Modelling and Projections held; Nairobi, Kenya. April 20-21st 2009; 2009. p. 1-19.

25. UNAIDS Reference Group on Estimates M, and Projections: Working Group on Measuring Concurrent Partnerships. HIV: consensus indicators are needed for concurrency. Lancet. 2010; 375:621-622. [PubMed: 19954832]

26. Kaufman JS, Cooper RS, McGee DL. Socioeconomic status and health in blacks and whites: the problem of residual confounding and the resiliency of race. Epidemiology. 1997; 8:621-628. [PubMed: 9345660]

27. CSDH. Final Report of the Commission on Social Determinants of health. Geneva: World Health Organization; 2008. Closing the gap in a generation: health equity through action on the social determinants of health.

28. Frieden TR. A framework for public health action: the health impact pyramid. Am J Public Health. 2010; 100:590-595. [PubMed: 20167880] 
TABLE 1

Distributions of Contextual Variables in the 2002 National Survey of Family Growth

\begin{tabular}{|c|c|c|c|}
\hline Contextual Variable & $25^{\text {th }}$ percentile & $50^{\text {th }}$ percentile & $75^{\text {th }}$ percentile \\
\hline Median household income 1999 (1999 USD) & 36,470 & 42,189 & 48,373 \\
\hline Sex ratio & 0.97 & 1.01 & 1.05 \\
\hline Percent of respondent's race in poverty & 7.2 & 9.8 & 19.1 \\
\hline Violent crime rate ${ }^{a}$ & 205.1 & 435.2 & 765.5 \\
\hline
\end{tabular}




\section{TABLE 2}

Crude and Adjusted ${ }^{a}$ Associations Between Individual Level Variables and Concurrent Partnerships ${ }^{b}$ in the 2002 National Survey of Family Growth

\begin{tabular}{lccccc}
\hline Individual Level Variable & \multicolumn{2}{c}{ Crude } & \multicolumn{2}{c}{ Adjusted $^{\boldsymbol{a}}$} \\
& POR & $\mathbf{9 5 \%}$ CI & \multicolumn{2}{c}{ POR } & $\mathbf{9 5 \%}$ CI \\
\hline Men & 1.11 & $(0.93,1.32)$ & 0.82 & $(0.68,1.00)$ \\
Age at interview (per decade) & 0.51 & $(0.46,0.56)$ & 0.86 & $(0.77,0.96)$ \\
Age at first sexual intercourse (per year) & 0.82 & $(0.77,0.88)$ & 0.87 & $(0.80,0.93)$ \\
High on drugs or alcohol during intercourse in past 12 months & 1.50 & $(1.38,1.63)$ & 1.28 & $(1.17,1.40)$ \\
Binge drinking in past 12 months & 1.50 & $(1.42,1.59)$ & 1.25 & $(1.19,1.32)$ \\
Unmarried & 9.07 & $(6.29,13.07)$ & 5.78 & $(3.96,8.44)$
\end{tabular}

${ }^{a}$ Prevalence odds ratios (POR) adjusted for other variables in the table

${ }^{b}$ In all sexually-experienced respondents $(\mathrm{N}=10,894)$ 


\section{TABLE 3}

Crude and Adjusted ${ }^{a}$ Associations between Group Level Variables and Concurrency in NSFG Counties with Low or Balanced Same-race Sex Ratios

\begin{tabular}{lcccc}
\hline Group Level Variable & \multicolumn{2}{c}{ Crude } & \multicolumn{2}{c}{ Adjusted $^{\boldsymbol{a}}$} \\
& POR & $\mathbf{9 5 \%}$ CI & POR & $\mathbf{9 5 \%}$ CI \\
\hline Sex Ratio: Low (<0.90) vs. Balanced (0.95-1.05) & 2.22 & $(1.69,2.94)$ & 1.46 & $(0.98,2.17)$ \\
\% of respondent's race in poverty (per 10 percentage point increase) & 1.52 & $(1.33,1.74)$ & 1.23 & $(0.98,1.54)$ \\
Violent crime (per 1,000 county residents per year) & 1.08 & $(1.04,1.13)$ & 1.05 & $(0.99,1.11)$ \\
$a_{\text {Prevalence odds ratio (POR) adjusted for other variables in the table }}$ & & & &
\end{tabular}


TABLE 4

Multilevel Analysis Combining Individual-Level and Group-Level Variables

\begin{tabular}{lcc}
\hline Variable & POR $^{\boldsymbol{a}}$ & $\mathbf{9 5 \%} \mathbf{C I}$ \\
\hline Low sex ratio (<0.9 vs 0.95-1.05) & $\mathbf{1 . 6 7}$ & $\mathbf{( 1 . 1 7 , 2 . 3 9 )}$ \\
\% of respondent's race in poverty (per 10 percentage point increase) & 1.18 & $(0.98,1.42)$ \\
Violent crime (per one unit increase in crimes per 1,000 county residents per year) & 1.04 & $(1.00,1.09)$ \\
Age at interview (per decade) & 0.60 & $(0.54,0.66)$ \\
Age first intercourse (per year) & 0.86 & $(0.82,0.90)$ \\
High on drugs or alcohol during intercourse in past 12 months & 1.51 & $(1.35,1.68)$ \\
Binge drinking during past 12 months & 1.42 & $(1.31,1.53)$ \\
Male & 0.68 & $(0.54,0.85)$ \\
$a_{\text {Prevalence odds ratios (POR) adjusted for all other variables in the table }}$ &
\end{tabular}

